\title{
Effect of thermophysical properties and processing conditions on primary dendrite arm spacing of nickel-base superalloys - numerical approach
}

\author{
Martin M. Franke ${ }^{1 \mathrm{a}}$, Michael Hilbinger ${ }^{1 \mathrm{~b}}$, Astrid Heckl ${ }^{2 \mathrm{c}}$, Robert F. Singer ${ }^{2 \mathrm{~d}}$ \\ ${ }^{1}$ Neue Materialien Fürth GmbH, Dr. - Mack - Str. 81, D-90762 Fürth, Germany \\ ${ }^{2}$ Institute of Science and Technology of Metals, Department of Materials Science and Engineering, \\ University of Erlangen, Martensstr. 5, D-91058 Erlangen, Germany \\ amartin.franke@nmfgmbh.de, ${ }^{b}$ michael.hilbinger@nmfgmbh.de, ${ }^{c}$ astrid.heckl@ww.uni-erlangen.de, \\ robert.singer@ww.uni-erlangen.de
}

Key words: superalloys, investment casting, numerical modeling, temperature gradient, solidification rate, primary dendrite arm spacing

\begin{abstract}
This paper presents the results of an investigation on the interrelationship between thermophysical properties, processing conditions and primary dendrite arm spacing for a nickelbase superalloy. The research was realized for CMSX-4, directionally solidified in a Bridgman furnace. For a systematic, fast and cost-efficient investigation numerical finite element models were applied. The numerical model, composed of thermophysical material data, geometric data and boundary conditions, was calibrated and experimentally validated. Microstructural parameters of the castings were determined for a broad range of processing conditions and varying thermophysical properties in order to study general influences. Withdrawal speed, furnace temperature, enthalpy of fusion, solidification range, heat conductivity and specific heat were varied accordingly. The primary dendrite arm spacing is predominantly influenced by withdrawal speed and furnace temperature, but shows only a weak dependency on thermophysical properties.
\end{abstract}

\section{Introduction}

Nickel-base superalloys are important high temperature materials used in particular for turbine blades in industrial gas turbines and aero engines. These materials show excellent mechanical properties up to high homologous temperatures and sustain thermal and mechanical stresses under extreme conditions. The fundamental aim of the current development of fuel-powered turbines is to increase the efficiency. To achieve a reduction in carbon dioxide emissions and fuel consumptions the firing temperature has to be increased and suitable materials have to be found. Prospective candidates are directionally solidified nickel-base superalloys with additions of refractory elements like tungsten (W), molybdenum (Mo) and rhenium (Re). To achieve a homogeneous element distribution and consequently optimal mechanical properties, precipitation-hardened nickel-base superalloys are heat treated after casting. The ease with which the segregation is removed is determined by the fineness of the microstructure, which is characterized by the dendrite arm spacing. A reduction in the primary dendrite arm spacing leads to a significant shortening of the annealing time, resultant costs and an improvement of the mechanical properties [1-2].

Accordingly the primary dendrite arm spacing is one of the most important microstructural characteristics. Several theoretical approaches formulate a correlation, whereupon the primary dendrite arm spacing $\lambda_{1}$ is predefined by temperature gradient $G$ and solidification rate $v$ [3-5]. The temperature gradient depends on thermophysical properties and processing conditions (e.g. temperature of heating furnace). The solidification rate is mainly dependent on the withdrawal speed. The present paper investigates the interrelationship between thermophysical properties, processing conditions and primary dendrite arm spacing of the nickel-base superalloy CMSX-4 in order to estimate the influence in general. For a systematic, fast and cost-efficient investigation the commercial simulation software ProCast (ESI Group, Paris, France) is applied. ProCast provides thermal analysis based on finite element method for the casting process. 
Numerical modeling. The casting consists of three cylindrical bars $(12 \mathrm{~mm}$ diameter, $180 \mathrm{~mm}$ length), which are fed by a common gating system. The numerical model of the casting unit represents the inhouse constructed Bridgman vacuum investment casting unit at the Institute of Science and Technology of Metals at the University of Erlangen. The casting unit consists of heating furnace, baffle, vacuum cooling chamber, chill plate and an apparatus to withdrawal the specimen. The mould is assembled from dense alumina rubalite tubes, mounted on a Ni-plate on top of a water-cooled copper chill plate (Fig. 1). Temperature dependent thermophysical data for the commercial nickel-base alloy CMSX-4 and the casting mould (Rubalit c799) have been obtained from literature [6-9] and JMatPro (Sente Software Ltd, Surrey, UK). Process conditions like temperatures of the heating furnace and the $\mathrm{Ni}$ - plate as well as the withdrawal speed were acquired from casting experiments.

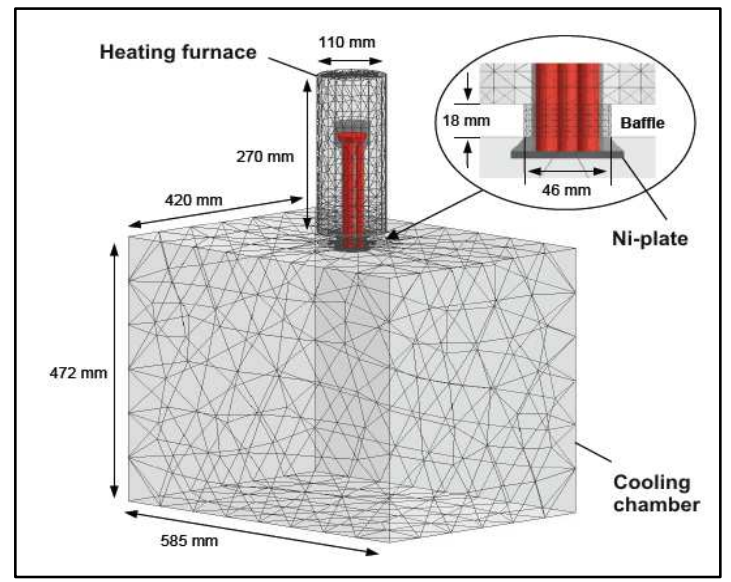

Fig. 1 Schematic illustration of Bridgman vacuum investment casting unit used for numeric modelling, including mould and casting. The numerical model represents the casting unit at the Institute of Science and Technology of Metals, University of Erlangen. The enclosure consists of heating furnace, baffle and cooling chamber. The casting is mounted on a Ni-plate, which is placed on top of a water-cooled chill plate.

Solidification conditions. The primary dendrite arm spacing $\lambda_{1}$ is a function of temperature gradient $G$ and solidification rate $v$. The mathematical correlation can be expressed as

$$
\lambda_{1}=K \cdot G^{-0.5} \cdot v^{-0.25}
$$

where $\mathrm{K}$ is a constant, determined to 1444 (with $G$ in $\mathrm{K} / \mathrm{m}, v$ in $\mathrm{m} / \mathrm{s}$ and $\lambda_{1}$ in $\mu \mathrm{m}$ ) for nickel-base superalloys [10]. It is possible to calculate $G$ and $v$ from the instationary numerical simulations. In Fig. 2a $G$ and $v$ are plotted against the distance to the Ni-plate for a furnace temperature of $1500{ }^{\circ} \mathrm{C}$ and a withdrawal speed of $8.53 \mathrm{~mm} / \mathrm{min}$. The corresponding dendrite arm spacing $\lambda_{1}$ resulting from Eq. 1 is illustrated in Fig. $2 b$.

(a)

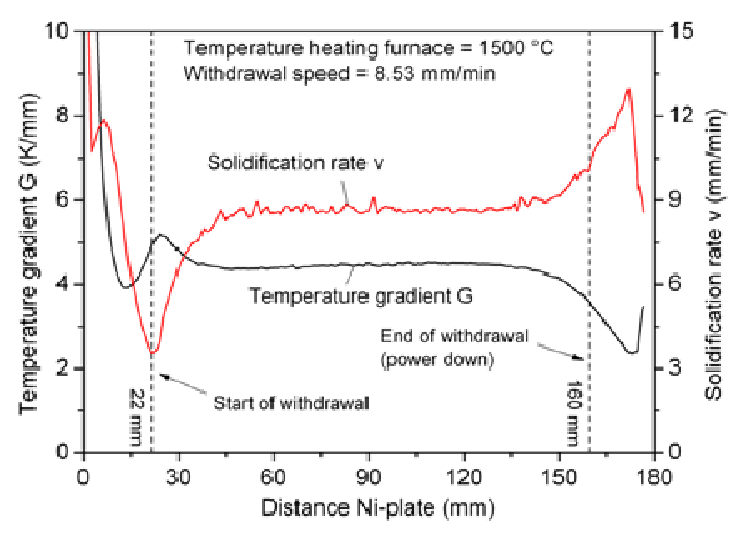

(b)

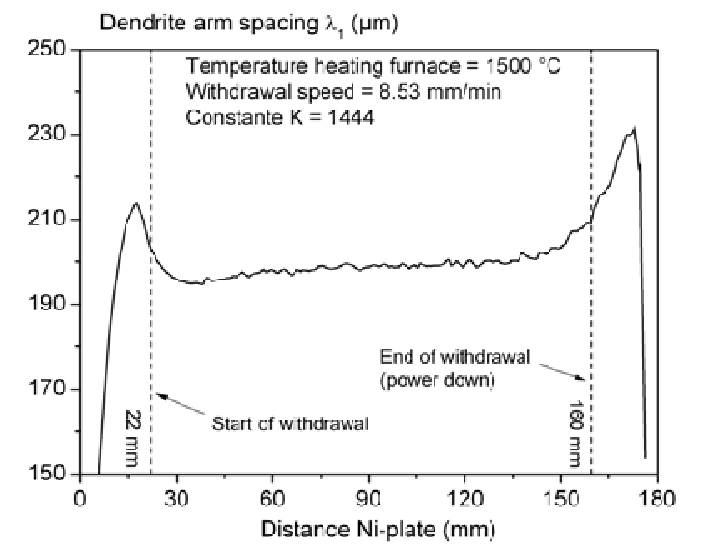

Fig. 2 (a) Temperature gradient $G$ and solidification rate $v$ versus the distance to the Ni-plate for a withdrawal speed of $8.53 \mathrm{~mm} / \mathrm{min}$ and a furnace temperature of $1500{ }^{\circ} \mathrm{C}$. $G$ and $v$ show an opposite tendency. Within the medium range both quantities are constant. From a distance of about $145 \mathrm{~mm}, G$ and $v$ are dominated by the shutdown and the gating system. (b) Primary dendrite arm spacing against distance to Niplate calculated from $G$ and $v$. 
At the beginning, the alloy solidifies rapidly because of the high temperature difference between the Ni-plate and the melt. Therefore the temperature gradient and the solidification rate are comparatively high. With progressing solidus - liquidus - interface towards the heating furnace, $G$ and $v$ decrease, until the baffle and the beginning withdrawal of the mould have an effect on temperature distribution within the casting. During further solidification, the solidification rate and the temperature gradient are constant and the alloy is solidifying directionally. Since geometry and heat capacity of the casting are limited, the influence of the cooling chamber on $G$ and $v$ increases towards the end of withdrawal. Thus the temperature gradient decreases and the solidification rate increases from a distance of about $145 \mathrm{~mm}$. This effect is fortified by the power down of the system at the end of withdrawal. The significant changes in $G$ and $v$ at the final stage of the solidification are caused by the gating system (Fig. 2a).

Calibration. The numerical model is calibrated by a suitable variation of several boundary conditions, so that the calculated primary dendrite arm spacing is equivalent to the experimentally derived data. The calibration is realized for three different sets of processing conditions. Geometric dimensions (casting unit, casting, mould) and thermophysical properties are fixed in the given system. Thus, the heat transfer coefficients are the main modification parameters. These have a great effect on temperature distribution within the casting geometry and consequently on the microstructure. Therefore the heat transfer coefficients are adjusted systematically until the calculated results agree with the casting tests. The starting estimates were obtained from literature [11- 12]. This approach is equivalent to an inverse determination of the heat transfer coefficients. Fig. 3 shows the calculated primary dendrite arm spacing in comparison to the experimentally derived values from metallographic micrographs.

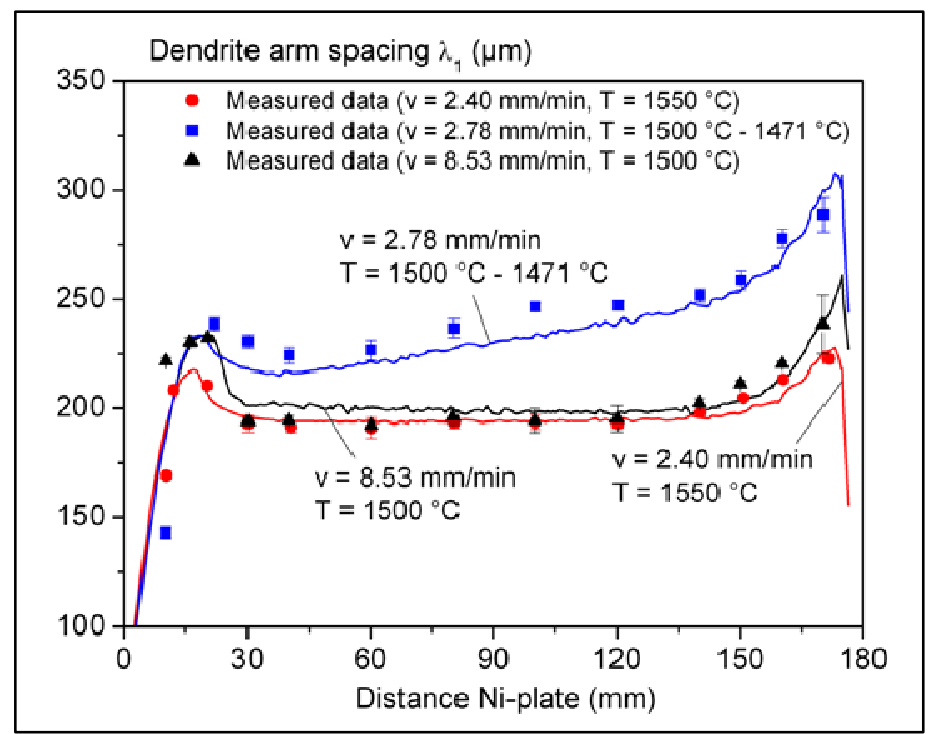

Fig. 3 Primary dendrite arm spacing in dependence of the distance to the Ni-plate for several furnace temperatures and withdrawal speeds. The solid lines represent calculated quantities; the points comply with measured data. The experimental and simulated values are in good agreement.

Result-sensitivity analysis. Generally the primary dendrite arm spacing depends on process conditions, thermophysical properties and density flow. In this section the influence of the process conditions and the thermophysical properties on the microstructure is presented. Therefore several parameters (furnace temperature, withdrawal speed, heat conductivity, specific heat, enthalpy of fusion and solidification range) are changed systematically as follows: The reference data for $\lambda_{1}$ is calculated for a furnace temperature of $1500{ }^{\circ} \mathrm{C}$, a withdrawal speed of $2.78 \mathrm{~mm} / \mathrm{min}$ and unmodified thermophysical properties of the commercial alloy CMSX-4. The calculations have been carried out in the steady state region of the casting at about $100 \mathrm{~mm}$ distance to the Ni-plate. Heat conductivity, specific heat and enthalpy of fusion are modified in the range of $\pm 30 \%$. The solidification range $\Delta T$ is changed according to Eq. 2 . Therein the liquidus temperture $T_{l}$ is modified between $1371{ }^{\circ} \mathrm{C}$ and $1401{ }^{\circ} \mathrm{C}$. The withdrawal speed is modified between $1 \mathrm{~mm} / \mathrm{min}$ and 9 $\mathrm{mm} / \mathrm{min}$, while heating furnace temperature is varied between $1400{ }^{\circ} \mathrm{C}$ and $1600{ }^{\circ} \mathrm{C}$. 


$$
\Delta T=\left(\frac{T_{l}-T_{l, C M S X-4}}{T_{l, C M S X-4}-T_{S, C M S X-4}}\right) \cdot 100 \%=\left(\frac{T_{l}-1381{ }^{\circ} \mathrm{C}}{1381{ }^{\circ} \mathrm{C}-1329{ }^{\circ} \mathrm{C}}\right) \cdot 100 \%
$$

$T_{l, C M S X-4}=$ liquidus temperature of CMSX-4; $T_{s, C M S X-4}=$ solidus temperature of CMSX-4

All results of the varied thermophysical properties are displayed in Fig. 4 as a function of primary dendrite arm spacing. An increase in solidification range, enthalpy of fusion and heat conductivity increases the primary dendrite arm spacing, while the specific heat has an opposite effect. In general, the effect of enthalpy of fusion and specific heat on microstructure is negligible. Solidification range and heat conductivity are showing a more pronounced influence on $\lambda_{l}$.

In contrast to the influence of the thermophysical properties, the achievable change in primary dendrite arm spacing based on processing conditions is clearly stronger. According to Fig. 5, $\lambda_{1}$ is decreasing with increasing withdrawal speed and furnace temperature.
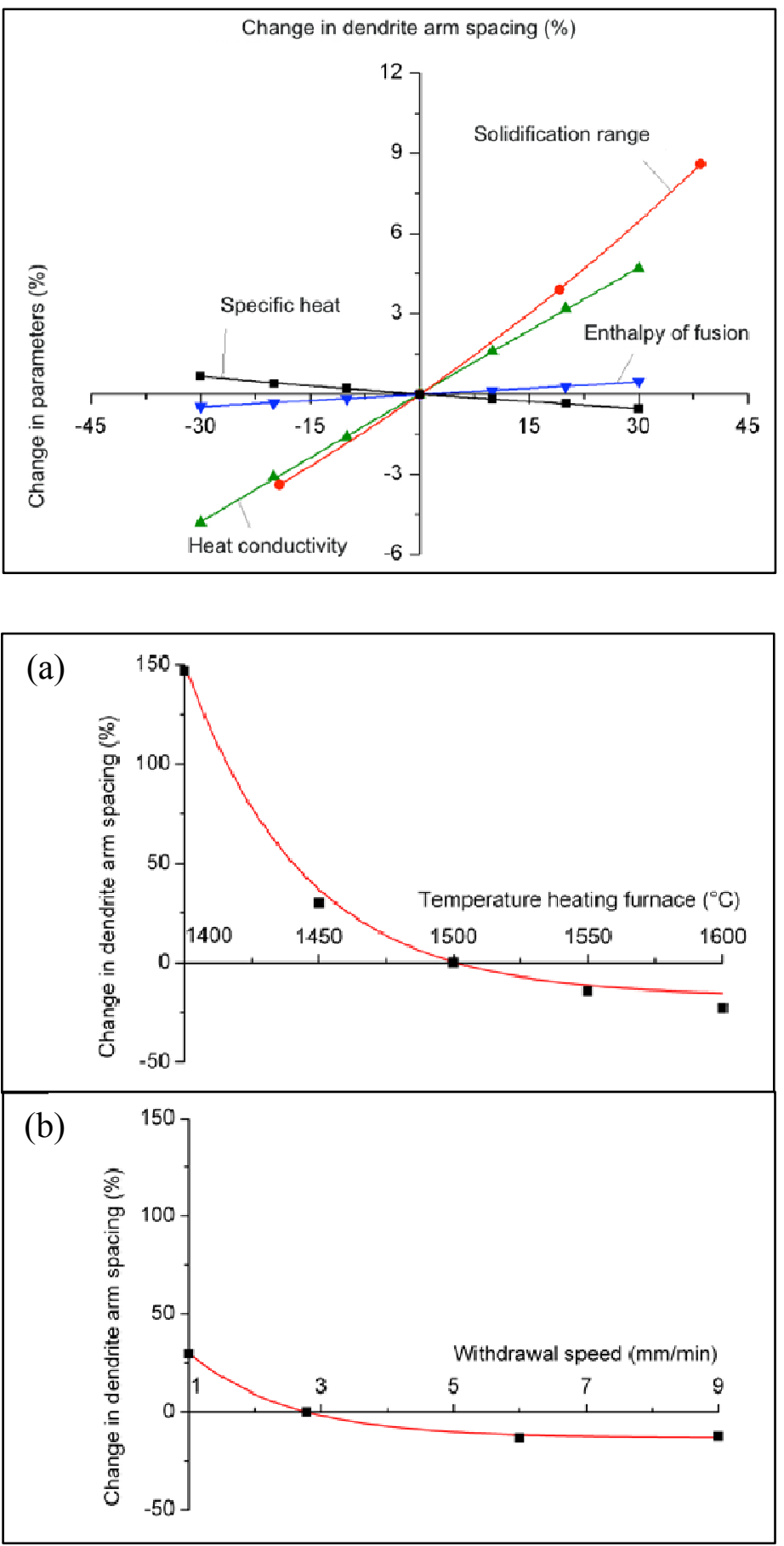

Fig. 4 Change in primary dendrite arm spacing as function of material-specific parameters for a furnace temperature of $1500{ }^{\circ} \mathrm{C}$ and a withdrawal speed of $2.78 \mathrm{~mm} / \mathrm{min}$. Calculated quantities are given as full symbols, solid lines correspond to approximated data.

Fig. 5 Change in primary dendrite arm spacing as function of (a) furnace temperature and (b) withdrawal speed. The furnace temperature was set to $1500{ }^{\circ} \mathrm{C}$ and the withdrawal speed to $2.78 \mathrm{~mm} / \mathrm{min}$. Calculated quantities are given as full symbols, solid lines correspond to approximated data. 
Discussion. The various thermophysical properties have quite different influences on primary dendrite arm spacing. With increasing liquidus-temperature the solidification range increases for a given solidus-temperature and the system overheat decreases. This leads to a reduction of the temperature gradient within the casting and an increase in primary dendrite arm spacing.

Increasing heat conductivity enhances the capability to transport thermal energy out of the specimen and thus decreases the temperature gradient. According to an inverse dependency between $G$ and $\lambda_{1}$ an increase in primary dendrite arm spacing is observable (Eq. 1).

With increasing specific heat, the solidus - liquidus - interface is moving towards the cooling chamber, because of a lowered thermal diffusivity. The higher temperature difference causes an increase of temperature gradient and therefore a decrease in $\lambda_{l}$ results.

The enthalpy of fusion describes the nascent thermal energy during solidification. With increasing latent heat the solidification rate is slowing down and the primary dendrite arm spacing increases (Eq. 1).

The reason for the different impact of thermophysical properties on primary dendrite arm spacing can be explained by the equation of heat conduction and its boundary conditions. The spatial and time resolved temperature distribution $\left(\nabla^{2} T ; \partial T / \partial t\right)$ is linked to the thermal diffusivity $(a)$, which is defined by the heat conductivity $(\lambda)$, specific heat $\left(c_{p}\right)$ and density $(\rho)$ (Eq. 3$)$. Therefore, the mentioned quantities should have the same effect on the primary dendrite arm spacing. However it is not the case in the investigated system, because the temperature distribution is determined by the boundary conditions (process temperatures), too. Due to the temperature difference between heating furnace and cooling chamber a dominant heat flow occurs (Fig. 6). The heating furnace corresponds to a heat source $\dot{W}$, which is observed while solving the equation of heat conduction (Eq. 3). Therefore the temperature distribution within the casting is determined not only by thermal diffusivity.

$$
\frac{\partial T}{\partial t}=a \cdot \nabla^{2} T+\frac{\dot{W}}{c_{p} \cdot \varrho}
$$

The furnace temperature has a direct impact on the temperature gradient within the casting. With increasing temperature difference between heating furnace and cooling chamber the temperature gradient is increasing too, wherefore a reduction in primary dendrite arm spacing is observable.

The solidification rate is immediately given by the withdrawal speed. An advance in withdrawal speed accelerates the solidification process consequently, since the position of solidus - liquidus interface is depending on the casting - transaction out of the heating furnace. According to equation Eq. 1 an enhancement in withdrawal speed and respectively in solidification rate is decreasing the primary dendrite arm spacing.

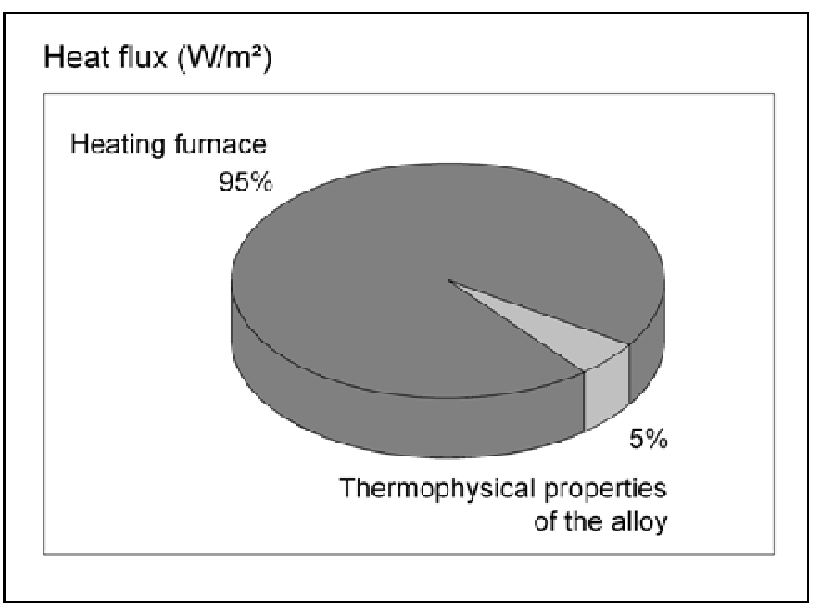

Fig. 6 The heat flux during the directional solidification depends on furnace temperature (heat source) and thermophysical properties of the alloy (thermal diffusivity, enthalpy of fusion). The furnace induces a dominant heat flow. The nascent heat caused by cooling and solidifying of the alloy is comparatively low. 
Summary. It was found from numerical calculations that the dendrite arm spacing is predominantly controlled by the withdrawal speed and the furnace temperature, while the thermophysical properties only have a minor influence. The basically low influence of heat conductivity, specific heat, enthalpy of fusion and solidification range on $\lambda_{1}$ is determined by process conditions. The heat flow within the casting unit is dominated by the heating capacity, which depends above all on the temperature of the heating furnace. Therefore the effect of thermophysical properties on $\lambda_{1}$ is comparatively low. To ensure constant casting parameters and reproducible process control, it is highly recommended that the withdrawal speed and furnace temperature are accurately monitored.

\section{References}

[1] M. McLean: Directionally solidified materials for high temperature service (The Metals Society 1983).

[2] M. Lamm: Einfluss der Erstarrungsbedingungen auf die mechanischen Eigenschaften von einkristallinen Superlegierungen bei großen Wandstärken (Dissertation, Technische Fakultät der Universität Erlangen - Nürnberg, 2007).

[3] J.D. Hunt: Solidification and casting of metals (The Metals Society 1979).

[4] W. Kurz, D.J. Fisher: Acta Metallurgica Vol. 29 (1981), p. 11

[5] R. Trivedi: Metallurgical and Materials Transactions Vol. 15 A (1984), p. 977

[6] L.A. Chapman, R. Morrell, P.N. Quested, R.F. Brooks, L.H. Chen, D. Ford: Properties of alloys and moulds relevant to investment casting (National Physical Laboratory, UK 2008).

[7] K.C. Mills: Recommend values of thermophysical properties for selected commercial alloys (National Physical Laboratory, UK 2002).

[8] M. Palumbo, D. Baldissin, L. Battezatti, O. Tassa, R. Wunderlich, H.J. Fecht, R. Brooks, K. Mills: Materials Science Forum Vol. 508 (2006), p. 591

[9] N. Hofmann: Simulation von Wärmstrahlung am Beispiel des Bridgman-Verfahrens zur gerichteten Erstarrung von Turbinenschaufeln (Dissertation, Rhein-Westfälische Technische Hochschule Aachen, 1995).

[10] P. Krug: Einfluss einer Flüssigmetallkühlung auf die Mikrostruktur gerichtet erstarrter Superlegierungen (Dissertation, Friedrich-Alexander Universität Erlangen-Nürnberg, 1998).

[11] A.J. Elliot, T.M. Pollock: Metallurgical and Materials Transactions Vol. 28 A (2007), p. 871

[12] C.V. Madhusudana: Thermal contact conductance (Springer Verlag, New York, 1996). 